\title{
High C-Reactive Protein and Low Albumin Levels Predict High 30-Day Mortality in Patients Undergoing Percutaneous Endoscopic Gastrotomy
}

\author{
Omer Karasahin ${ }^{\mathrm{a}}$, Pinar Tosun Tasar ${ }^{\mathrm{b}}$, f, Ozge Timur ${ }^{\mathrm{c}}$, Dogan Nasir Binicic ${ }^{\mathrm{c}}$, \\ Tugba Kiper Yilmaz ${ }^{c}$, Adem Aslan ${ }^{\text {, }}$ Sevnaz Sahin ${ }^{\mathrm{e}}$
}

\begin{abstract}
Background: Percutaneous endoscopic gastrotomy (PEG) enables long-term enteral feeding. The aim of this study was to identify biomarkers that may guide the decision of whether to perform the elective procedure of PEG.

Methods: The medical records of all patients who underwent PEG in our hospital from 2010 to 2016 were screened retrospectively. Patients with mortality within a 30-day follow-up period and those without were compared using the Chi-square test, and continuous variables were compared with the Kruskal-Wallis and Mann-Whitney U tests. Receiver operating characteristic (ROC) curve analysis was used to demonstrate the ability of biomarkers to predict mortality; a cut-off point was determined and its sensitivity, specificity, and positive and negative predictive values were calculated. The Youden index was used to determine the cut-off point. Kaplan-Meier analysis was used to identify PEG-related mortality risk factors and a Cox regression model was applied for risk characterization.
\end{abstract}

Results: A total of 120 patients who underwent PEG were evaluated in the study. The mean age was $67.00 \pm 18.00$ years. The most common indication for PEG was cerebrovascular disease, in 69 (57.5\%) of the patients. Infection of the PEG site was most common within 14 days after PEG tube placement, occurring in 13 patients $(10.3 \%)$. The mortality rate among patients with post-PEG infection was $68.2 \%$, significantly higher than in patients without infection $(\mathrm{P}=0.012)$.

Manuscript submitted May 20, 2017, accepted May 31, 2017

${ }^{a}$ Infectious Diseases Clinic, Erzurum Regional Training and Research Hospital, Erzurum, Turkey

${ }^{\mathrm{b}}$ Geriatrics Clinic, Erzurum Regional Training and Research Hospital, Erzurum, Turkey

'Internal Medicine Clinic, Erzurum Regional Training and Research Hospital, Erzurum, Turkey

${ }^{\mathrm{d}}$ General Surgery Clinic, Erzurum Regional Training and Research Hospital, Erzurum, Turkey

eDepartment of Internal Medicine, Department of Geriatrics, Ege University School of Medicine, Izmir, Turkey

${ }^{f}$ Corresponding Author: Pinar Tosun Tasar, Geriatrics Clinic, Erzurum Regional Training and Research Hospital, Erzurum, Turkey.

Email: pinar.tosun@gmail.com
Thirty-four patients (28.3\%) died within 30 days of undergoing PEG. CRP values $\geq 78.31 \mathrm{mg} / \mathrm{L}$ increased mortality by 8.756 -fold, and albumin levels $<2.71 \mathrm{~g} / \mathrm{dL}$ increased mortality by 2.255 -fold.

Conclusion: Our results indicate that the presence of both high CRP level and low albumin level were associated with significantly higher rate of mortality $(73.1 \%)$ in patients who underwent PEG.

Keywords: Mortality; PEG

\section{Introduction}

The purpose of enteral nutrition is to protect gastrointestinal mucosal integrity, thereby maintaining mucosal barrier function, intestinal immunity, and the normal flora [1]. Percutaneous endoscopic gastrostomy (PEG) allows long-term enteral feeding through a gastrostomy tube for various indications causing malnutrition in patients with normally functioning bowels [2].

In the literature, 30-day mortality rates reported for patients with PEG range from $2.4 \%$ to $22.5 \%$ [2-5]. It has been emphasized that short-term, less invasive methods like nasogastric (NG) feeding may be preferable in cases where the patient is unlikely to survive for 30 days after PEG placement [6]. Therefore, in this study, we aimed to identify biomarkers that may guide the decision of whether to perform the elective procedure of PEG.

\section{Materials and Methods}

We included all patients who underwent PEG at the Erzurum Regional Hospital between January 1, 2010 and December 31, 2016. Data were collected by retrospective screening of patients' medical records and the hospital records system. Categorical descriptive data were expressed as frequency distribution and percentage; continuous variables were expressed as mean \pm standard deviation and median (maximum - minimum).

\section{Definition of infection site}

Aspiration pneumonia refers to the pulmonary consequences 
Table 1. Characteristics of Patients Who Underwent PEG

\begin{tabular}{|ll}
\hline Characteristics & Number (\%) \\
\hline $\begin{array}{l}\text { Age } \\
\quad<65\end{array}$ & $42(35 \%)$ \\
$\quad \geq 65$ & $78(65.0 \%)$ \\
\hline $\begin{array}{l}\text { Indication for PEG } \\
\quad \text { Cerebrovascular disease }\end{array}$ & $69(57.5 \%)$ \\
Neurologic disease & $25(20.8 \%)$ \\
Dementia & $16(13.3 \%)$ \\
Malignancy & $10(8.3 \%)$ \\
Department conducting PEG & \\
Intensive care unit & $43(35.8)$ \\
Inpatient units & $77(64.2 \%)$ \\
\hline
\end{tabular}

resulting from this abnormal entry of fluid, particulate exogenous substances, or endogenous secretions into the lower airways [7].

The presence of the following criteria is necessary to diagnose aspiration pneumonia [8]: 1) infiltration in chest X-ray; 2) the presence of at least one of the major criteria (cough, sputum, fever) or at least one of the minor criteria (dyspnea, chest pain, consciousness change, consensus on physical examination, leukocyte count 12,000 and above); and 3) aspiration to be witnessed or to find a risk factor for aspiration.

PEG site infection was defined to be positive if three or more of the following criteria were observed: erythema, induration, exudate and/or purulent secretion [9].

Blood stream infection required one of the following: 1) recognized pathogen in the blood and pathogen not related to an infection at another site; or 2) fever, chills, or hypotension; and any of the following: 1) a common skin contaminant is isolated from at least two blood cultures drawn on separate occasions, and the organism is not related to infection at another site; 2) a common skin contaminant is isolated from blood culture in a patient with an intravascular device, and the physician institutes appropriate antimicrobial therapy; 3) a positive antigen test on blood and the organism is not related to infection at another site [10].

Bloodstream infection is the isolation of a bacterial or fungus originating in the blood stream of an infection at any anatomical site of the body [10].

Patients with mortality within 30 days and those who survived for more than 30 days after the PEG procedure were compared using the Chi-square test. Continuous variables did not meet the assumptions of parametric hypothesis and were compared with the non-parametric Kruskal-Wallis and MannWhitney U tests.

Receiver operating characteristic (ROC) curve analysis was used to demonstrate the predictive value of albumin, Creactive protein (CRP), lymphocyte ratio, hemoglobin, and leukocyte number on mortality. A cut-off point was determined and its sensitivity, specificity, positive predictive value (PPV) and negative predictive value (NPV) were calculated. The Youden index $(\mathrm{J}=$ sensitivity + specificity -1$)$ was used to
Table 2. Distribution of the Microbial Agents of Infections Developed After Percutaneous Endoscopic Gastrotomy

\begin{tabular}{lll}
\hline Infection & Agent & $\begin{array}{l}\text { Number } \\
(\mathbf{\%})\end{array}$ \\
\hline PEG site infection & & $13(10.3 \%)$ \\
& Klebsiella spp. & $4(30.7 \%)$ \\
& Enterococcus faecium & $2(15.3 \%)$ \\
& Escherichia coli & $2(15.3 \%)$ \\
& Acinetobacter baumannii & $2(15.3 \%)$ \\
& Staphylococcus aureus & $1(7.6 \%)$ \\
& Proteus mirabilis & $1(7.6 \%)$ \\
& Stenotrophomonas maltophilia & $1(7.6 \%)$ \\
Bloodstream infection & & $6(5.0 \%)$ \\
& Candida albicans & $5(83.3 \%)$ \\
& Enterococcus faecium & $1(16.7 \%)$ \\
Aspiration pneumonia & & $3(2.5 \%)$ \\
& Klebsiella spp. & $3(100 \%)$ \\
\hline
\end{tabular}

determine the cut-off point.

Kaplan-Meier (log-rank) analysis was used to identify PEG-related mortality risk factors, then a Cox regression model was applied for risk characterization (model: forward: likelihood ratio (LR) entry: 0.05 and removal: 0.10 ).

$\mathrm{P}<0.05$ was accepted as statistically significant. Data were analyzed using SPSS 15.0 statistical software package.

\section{Results}

A total of 120 patients who underwent PEG were evaluated in the study. The mean age was $67.00 \pm 18.00$ years and median age was 72 years (range, 16 - 90 years). Seventy $(58.3 \%)$ of the patients were male. The most common indication for PEG was cerebrovascular disease, present in $69(57.5 \%)$ of the patients (Table 1).

Within 14 days after PEG placement, 13 patients $(10.3 \%)$ developed infection of the PEG site, six patients $(5.0 \%)$ had bloodstream infections, and three patients $(2.5 \%)$ developed aspiration pneumonia. The mortality rate among patients with post-PEG infection was $68.2 \%$, significantly higher than in patients without infection $(\mathrm{P}=0.012)$. The distribution of infectious agent according to infection type is presented in Table 2.

Thirty-four patients $(28.3 \%)$ died within 30 days of undergoing PEG. Of these patients, $64.4 \%$ were in the intensive care unit. Mortality was significantly higher among patients in intensive care compared to those whose PEG was performed in inpatient units $(\mathrm{P}<0.001)$. Table 3 shows the patients' comorbid conditions and biomarker levels assessed on the day PEG was performed, grouped according to 30-day mortality.

Analysis of the biomarkers' diagnostic power is presented in Table 4. CRP value was found to have the greatest diagnos- 
Table 3. Biomarker Levels and Comorbidities in Patients Based on 30-Day Mortality

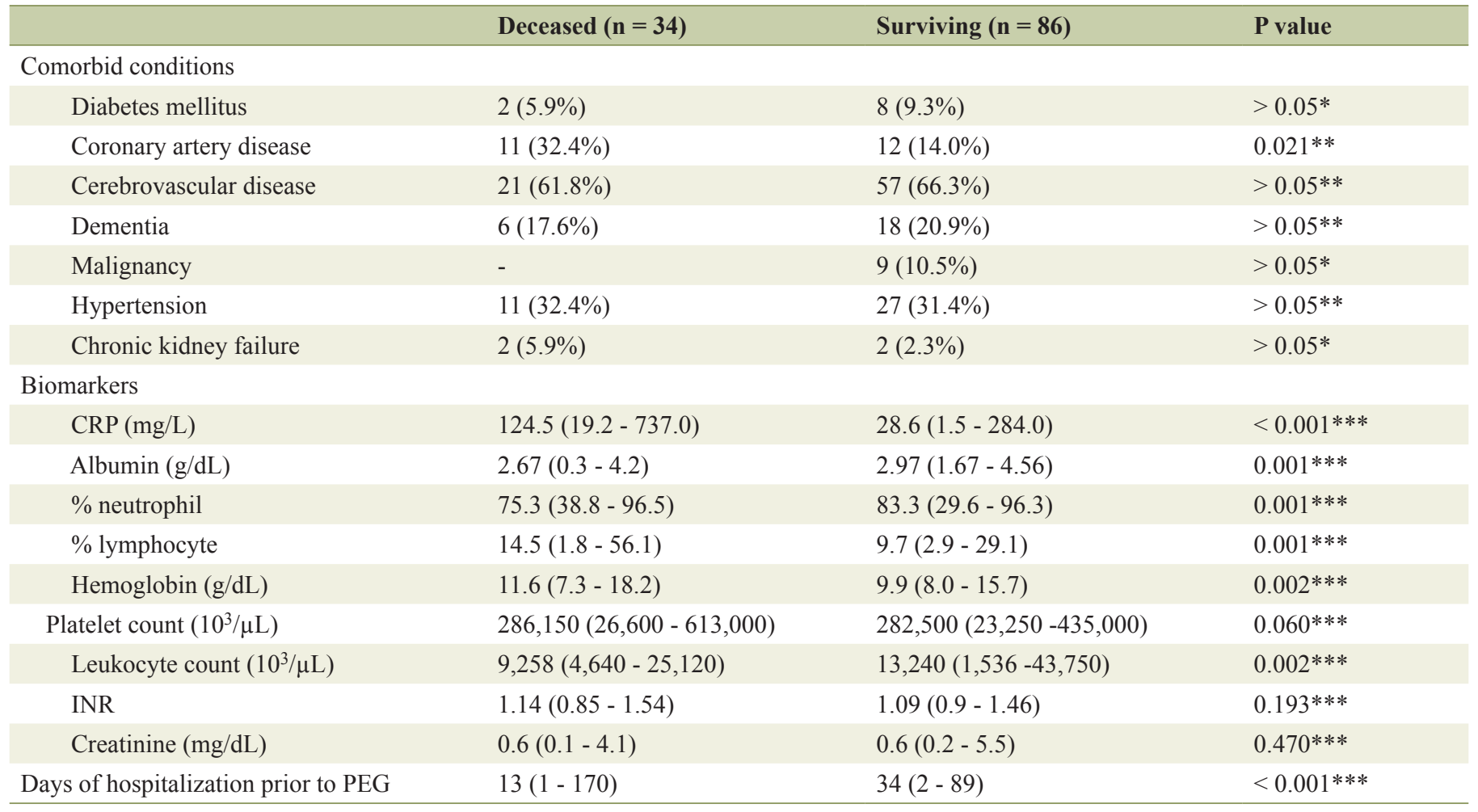

${ }^{*}$ Fisher's exact test. ${ }^{* *}$ Chi-square test. ${ }^{* *}$ Mann-Whitney $U$ test.

tic power (area under the curve: $82.5 \%$ (confidence interval: $74.9-90.2 \%)$ ).

The Cox regression analysis included variables which emerged as significant in Kaplan-Meier analysis: lymphocyte and neutrophil percentages, CRP, albumin, hemoglobin, leukocyte count, and coronary artery disease. CRP values $\geq 78.31$ $\mathrm{mg} / \mathrm{L}$ increased mortality by 8.756 -fold, and albumin levels $<$ $2.71 \mathrm{~g} / \mathrm{dL}$ increased mortality by 2.255 -fold (confidence interval: $1.110-4.579, \mathrm{P}=0.024)$.

A graph of 30-day survival using both CRP and albumin is shown in Figure 1. Patients with CRP values under $78.3 \mathrm{mg} / \mathrm{L}$ had a median survival of 28.6 days (27.3 - 30.0 days), while patients with CRP values over $78.3 \mathrm{mg} / \mathrm{L}$ had a median survival of 20.2 days (17.4 - 23.0 days). Patients with albumin levels under $2.71 \mathrm{~g} / \mathrm{dL}$ had median survival of 21.3 days (18.2 - 24.5 days), whereas patients with albumin levels over $2.71 \mathrm{~g} / \mathrm{dL}$ had a mean survival of 27.1 days (25.5 - 28.7 days).

\section{Discussion}

PEG allows long-term feeding via enteral nutrition for patients who are unable to take oral nutrition [11]. Being a surgical procedure, PEG introduces various complications. PEG-related complications are reported in $13.2-50 \%$ of patients who undergo the procedure $[5,12,13]$. The most important of these complications are aspiration pneumonia, esophageal perforation, bleeding, tube occlusion, anesthesia-related side effects, and infection of the wound site [11]. The incidence of local or lifethreatening systemic infections following PEG is reported as $4-60 \%[14,15]$. The infection rate among patients analyzed in our study was $18.8 \%$ and most infections were at the incision

Table 4. Evaluation of Biomarkers Using ROC Analysis

\begin{tabular}{|lllllll} 
& Cut-off value & P value & Sensitivity (\%) & Specificity (\%) & $\begin{array}{l}\text { Positive predictive } \\
\text { value (\%) }\end{array}$ & $\begin{array}{l}\text { Negative predictive } \\
\text { value (\%) }\end{array}$ \\
\hline CRP $(\mathrm{mg} / \mathrm{L})$ & 78.3 & $<0.001$ & $85.2(82.8-87.3)$ & $74.5(71.6-77.1)$ & $76.9(74.9-78.8)$ & $83.4(81.2-85.4)$ \\
Albumin $(\mathrm{g} / \mathrm{dL})$ & 2.71 & 0.001 & $75.5(72.7-78.1)$ & $61.8(58.7-64.8)$ & $66.8(64.4-68.3)$ & $71.6(69.1-73.9$ \\
\% neutrophil & 75.89 & 0.001 & $82.3(79.7-84.6)$ & $53.1(49.9-56.2)$ & $63.7(62.0-65.3)$ & $75(72.1-77.6)$ \\
\% lymphocyte & 14.42 & 0.001 & $51.8(48.6-54.9)$ & $85.3(82.9-87.4)$ & $77.8(75.0-80.5)$ & $63.9(62.2-65.4)$ \\
Hemoglobin $(\mathrm{g} / \mathrm{dL})$ & 9.94 & 0.002 & $73.8(70.9-76.5)$ & $58.9(55.7-61.9)$ & $64.2(62.3-66.1)$ & $69.2(66.6-71.6)$ \\
Leukocyte count $\left(10^{3} / \mu \mathrm{L}\right)$ & 10,530 & 0.002 & $67.6(63.9-69.8)$ & $66.7(63.6-69.6)$ & $67.0(64.8-69.1)$ & $66.4(64.4-68.7)$ \\
\hline
\end{tabular}




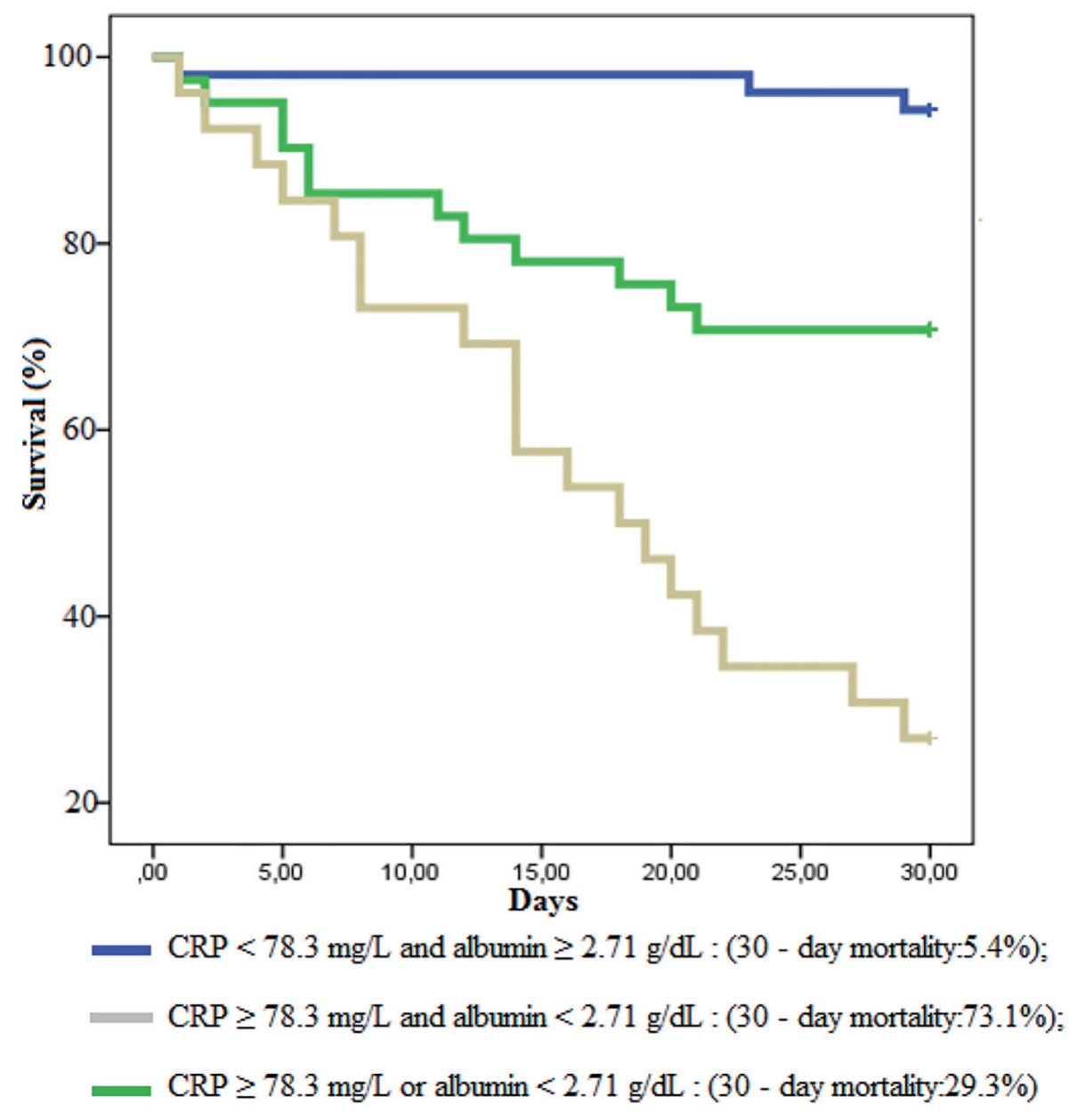

Figure 1. Survival graph based on CRP and albumin.

site, consistent with the literature. Similar to previous studies, the infectious agents we identified were predominantly gramnegative microorganisms, but we also detected polymicrobial infections in our study [16]. In the literature, the 30-day mortality rate for PEG patients has been reported as 2.4-22.5\% [25]. Compared to previous studies, the 30 -day mortality rate in our study was high at $28.3 \%$. This is likely related to the high mortality rate among patients who underwent PEG in intensive care $(66.4 \%)$. Due to the high mortality rates and complications, our objective in the present study was to identify biomarkers that may guide the decision to perform PEG.

Albumin and CRP levels have been used in PEG patients to predict short-term mortality and detect acute conditions which may affect prognosis [4, 17-20]. Bloomberg et al found that CRP level over $10 \mathrm{mg} / \mathrm{L}$ and albumin under $3.0 \mathrm{~g} / \mathrm{dL}$ was an independent risk factor for post-PEG mortality. In addition, using those cut-off points, the authors demonstrated a $20.5 \%$ mortality rate among patients with high CRP and low albumin levels [4]. In a similar study, the mortality rate was approximately $60 \%$ among patients with CRP over $21.5 \mathrm{mg} / \mathrm{L}$ and albumin under $3.15 \mathrm{~g} / \mathrm{dL}$ [5]. Another study that identified CRP elevation after $\mathrm{PEG}$ as an independent risk factor reported a mortality rate of $18 \%$ at CRP levels over $50 \mathrm{mg} / \mathrm{L}$. The cut-off point for low albumin level as an independent risk factor for post-PEG mortality in dementia patients was reported as $2.8 \mathrm{~g} /$ $\mathrm{dL}$ [20]. Cut-off points in our study were $78.3 \mathrm{mg} / \mathrm{L}$ for CRP and $2.71 \mathrm{~g} / \mathrm{dL}$ for albumin. Consistent with previous studies, these biomarkers were identified as an independent risk factor for mortality, with $73.1 \%$ of the patients with high $\mathrm{CRP} /$ low albumin levels surviving less than 30 days post-PEG.

We determined a higher cut-off value for CRP than that reported in previous studies. This may be due to the inclusion in our study of patients in intensive care, patients on mechanical ventilators, and patients at high risk of infection. Although elevated CRP does not reflect a patient's overall condition and may be considered a limitation of the present study, we believe it is effective for our purpose because it serves as evidence of infection and indicates that PEG should be postponed.

Low albumin and high CRP levels have been reported previously as indicators of malnutrition, inflammation, and postoperative infection [4, 21, 22]. As PEG is not an emergent procedure, it can be deferred; authors have reported that it can be performed after an underlying acute condition is investigated. Meanwhile, nutritional support can be provided via less invasive methods such as parenteral feeding or nasogastric catheter [4]. Therefore, caution must be exercised when 
deciding when to perform PEG, as with any elective surgical intervention, especially in patients with high CRP and low albumin levels.

\section{Conclusion}

Our results indicate that the presence of both high CRP level and low albumin level were associated with significantly higher rate of mortality (73.1\%) in patients who underwent PEG. High CRP and low albumin levels undoubtedly constitute a mortality risk for all surgical procedures. Furthermore, low albumin levels are an indicator of malnutrition, which is the reason PEG is performed. However, patients who die within 30 days are not able to benefit from PEG. Therefore, guided by albumin and CRP, underlying acute conditions must be identified and alleviated. We believe that providing nutritional support by alternative routes allows the PEG procedure to be deferred until it is safer to perform.

\section{References}

1. Onder A, Kapan M, Arikanoglu Z, Gul M, Bestas R, Palanci Y, Karaman H, et al. Percutaneous endoscopic gastrostomy: mortality and risk factors for survival. Gastroenterology Res. 2012;5(1):21-27.

2. Grant MD, Rudberg MA, Brody JA. Gastrostomy placement and mortality among hospitalized Medicare beneficiaries. JAMA. 1998;279(24):1973-1976.

3. Laskaratos FM, Walker M, Gowribalan J, Gkotsi D, Wojciechowska V, Arora A, Jenkins A. Predictive factors for early mortality after percutaneous endoscopic and radiologically-inserted gastrostomy. Dig Dis Sci. 2013;58(12):3558-3565.

4. Blomberg J, Lagergren P, Martin L, Mattsson F, Lagergren J. Albumin and C-reactive protein levels predict short-term mortality after percutaneous endoscopic gastrostomy in a prospective cohort study. Gastrointest Endosc. 2011;73(1):29-36.

5. Lee C, Im JP, Kim JW, Kim SE, Ryu DY, Cha JM, Kim $\mathrm{EY}$, et al. Risk factors for complications and mortality of percutaneous endoscopic gastrostomy: a multicenter, retrospective study. Surg Endosc. 2013;27(10):3806-3815.

6. Jain R, Maple JT, Anderson MA, Appalaneni V, BenMenachem T, Decker GA, Fanelli RD, et al. The role of endoscopy in enteral feeding. Gastrointest Endosc. 2011;74(1):7-12.

7. Marik PE. Aspiration pneumonitis and aspiration pneumonia. N Engl J Med. 2001;344(9):665-671.

8. Leroy $\mathrm{O}$, Vandenbussche $\mathrm{C}$, Coffinier $\mathrm{C}$, Bosquet $\mathrm{C}$, Georges H, Guery B, Thevenin D, et al. Community-acquired aspiration pneumonia in intensive care units. Epi- demiological and prognosis data. Am J Respir Crit Care Med. 1997;156(6):1922-1929.

9. Zopf Y, Konturek P, Nuernberger A, Maiss J, Zenk J, Iro $\mathrm{H}$, Hahn EG, et al. Local infection after placement of percutaneous endoscopic gastrostomy tubes: a prospective study evaluating risk factors. Can J Gastroenterol. 2008;22(12):987-991.

10. Garner JS, Jarvis WR, Emori TG, Horan TC, Hughes JM. CDC definitions for nosocomial infections, 1988. Am J Infect Control. 1988;16(3):128-140.

11. Abuksis G, Mor M, Segal N, Shemesh I, Plout S, Sulkes J, Fraser GM, et al. Percutaneous endoscopic gastrostomy: high mortality rates in hospitalized patients. Am J Gastroenterol. 2000;95(1):128-132.

12. Pruthi D, Duerksen DR, Singh H. The practice of gastrostomy tube placement across a Canadian regional health authority. Am J Gastroenterol. 2010;105(7):1541-1550.

13. Sheehan JJ, Hill AD, Fanning NP, Healy C, McDermott EW, O'Donoghue DP, O'Higgins NJ. Percutaneous endoscopic gastrostomy: 5 years of clinical experience on 238 patients. Ir Med J. 2003;96(9):265-267.

14. Schapiro GD, Edmundowicz SA. Complications of percutaneous endoscopic gastrostomy. Gastrointest Endosc Clin N Am. 1996;6(2):409-422.

15. Chowdhury MA, Batey R. Complications and outcome of percutaneous endoscopic gastrostomy in different patient groups. J Gastroenterol Hepatol. 1996;11(9):835-839.

16. Rolston KV, Mihu C, Tarrand JJ. Current microbiology of percutaneous endoscopic gastrostomy tube (PEG tube) insertion site infections in patients with cancer. Support Care Cancer. 2011;19(8):1267-1271.

17. Lang A, Bardan E, Chowers Y, Sakhnini E, Fidder HH, Bar-Meir S, Avidan B. Risk factors for mortality in patients undergoing percutaneous endoscopic gastrostomy. Endoscopy. 2004;36(6):522-526.

18. Martin L, Lagergren J, Blomberg J, Johar A, Bosaeus I, Lagergren $\mathrm{P}$. Phase angle as a prognostic marker after percutaneous endoscopic gastrostomy (PEG) in a prospective cohort study. Scand J Gastroenterol. 2016;51(8):1013-1016.

19. Figueiredo FA, da Costa MC, Pelosi AD, Martins RN, Machado L, Francioni E. Predicting outcomes and complications of percutaneous endoscopic gastrostomy. Endoscopy. 2007;39(4):333-338.

20. Higaki F, Yokota O, Ohishi M. Factors predictive of survival after percutaneous endoscopic gastrostomy in the elderly: is dementia really a risk factor? Am J Gastroenterol. 2008;103(4):1011-1016; quiz 1017.

21. Stephens NA, Skipworth RJ, Fearon KC. Cachexia, survival and the acute phase response. Curr Opin Support Palliat Care. 2008;2(4):267-274.

22. McMillan DC. An inflammation-based prognostic score and its role in the nutrition-based management of patients with cancer. Proc Nutr Soc. 2008;67(3):257-262. 